\title{
Australian Journal of Crop Science \\ Performance of crops under Eucalyptus tree-crop mixtures and its potential for adoption in agroforestry systems
}

\author{
Stanley W. Nadir ${ }^{1 *}$, Wilson K. Ng'etich ${ }^{2}$, Syphiline J. Kebeney ${ }^{2}$ \\ ${ }^{1}$ Kenya Forestry Research Institute (KEFRI) P.O. Box 20412-00200, Nairobi, Kenya \\ ${ }^{2}$ Department of Soil Science, University of Eldoret P.O. Box 1125-30100, Eldoret, Kenya
}

*Corresponding author: stanleynadir@yahoo.com

\begin{abstract}
Competition for scarce land resources between food crops and trees has intensified and there is need for a balance to accommodate both, either in rotation programs or in agroforestry systems. Successful intercropping of Eucalyptus trees with crops is hindered by competition for light between trees and crops, soil nutrient dynamics and the allelopathy from Eucalyptus trees. The aim of this study was to establish and assess the performance of farm crops under Eucalyptus grandis tree plantations so as to evaluate the potential of the trees for agroforestry. The crops i.e. common beans, Irish potatoes and black Nightshade (Solanum villosum) were planted along rows of Eucalyptus trees ( 3 and 6 years) in plot sizes of $4 \mathrm{~m}$ by $2 \mathrm{~m}$ adopting a factorial arrangement in RCBD with open field as control. The assessment of the performance of the crops was mainly on; germination, Leaf Area Index (LAI) and possible yields. In addition, the amount of photosynthetically active radiation (PAR) reaching the understory crops was measured. From the results, Germination of crops under trees was higher than in the open field. Germination was delayed under trees when compared to those grown in the open field. The age differences in the Eucalyptus tree plantations had no significant effect on the amount of PAR reaching the understory crops. The leaf area index (LAI) of the understory crops was significantly affected by Eucalyptus trees of different ages $(p<.001)$. The crops grown under Eucalyptus trees gave higher yields compared to crops grown in open fields but not fertilized. The effect of Eucalyptus plantation age significantly affected the yields of beans and potatoes $(p<.001)$ but not nightshade; therefore, the vegetable can be grown under Eucalyptus tree shade without reduction in yield. Irish potato and common beans are potential crops for agroforestry with Eucalyptus trees but need further research as their yields were low and had selected disease incidences.
\end{abstract}

Keywords: Canopy, common beans, Leaf area index (LAI), nightshade, photo-synthetically active radiation (PAR), Irish potatoes, yield.

\section{Introduction}

Eucalyptus tree species were introduced in Kenya by the British in 1902 to provide energy for their locomotives (Kenya Forest Service, 2009). The species is widely grown because of its fast growth, multiple uses, and suitability to small scale farmers. In the year 2009, the area under Eucalyptus species in the country was estimated to be about 100,000 ha of plantations; 15,000 ha in the gazetted forests, 35,000 ha planted by private companies and 50,000 ha by farmers (Oballa et al., 2010). Eucalyptus spp are distributed in different agro-ecological zones throughout the country with common species being $E$. grandis, E. saligna, $E$. globulus, Eregnans, E. paniculata, E. maculata, $E$ camaldulensis, E. citriodora, E. tereticornis, Europhylla and E. hybrids (Kenya Forest Service, 2009). Competition for scarce land resources between food crops and these Eucalyptus trees has intensified hence there is need for a balance to accommodate both, either in rotation programs or in agroforestry systems. According to FAO (2006), population increase and change in the eating habits will cause an increment in world food requirements of $80-120 \%$ by 2050 hence there is need to close this gap through agroforestry as one of the solutions. Successful intercropping of Eucalyptus trees with food crops is hindered by competition for light between trees and crops, the soil nutrient dynamics and the allelopathy effects from Eucalyptus trees. The allelochemicals present in the soils under Eucalyptus (Sasikumar et al., 2002) may influence crop production but its effects are masked by those effects resulting from competition for light and nutrients. Recent studies by Mugunga (2016), suggest integration of Eucalyptus trees and crops is possible especially in spatially zoned agroforestry systems or as mixtures although the edge effect interactions between trees and crops seemed to affect crop yields. Agroforestry is also an option to increase tree cover outside the forests especially in highly populated areas and low potential nonproductive agricultural lands and in fact accommodation of more trees on arable agricultural lands through agroforestry increases on-farm tree regeneration (Licker et al. 2010). The productivity of the tree-crop mixtures has known to be influenced by the light interception by different components of multi-layered agroforestry systems (Nair, 1993; Loomis and Connor, 2002). 
The amount of incident solar radiation captured by different components in tree-crop mixtures is influenced by levels of water and nutrients present (Loomis and Connor, 2002). Agroforestry systems modify the microclimate especially radiation intensities, relative humidity, carbon dioxide concentration and soil conditions to understory crops (Dhillon et al., 2016). The performance of crops under reduced light conditions in the tree-crop mixtures remain an obstacle in accommodating both trees and crops on farms of the agroforestry hence need for this research. To modify existing or create new agroforestry systems, interactions of tree crop mixtures should be well researched to provide needed information especially the newly created patterns for light capture (Johar et al., 2017; Whiting, 2011). The productivity of crop canopies has been quantified using concepts of Leaf Area Index (LAI) and the Crop Growth Rate (CGR) as estimators of the crop's ability to capture light energy available for plant growth (Campillo et al., 2012), therefore necessary tools used to assess productivity in this study. Selection of crop species to be used in agroforestry systems is based on cultural, economic as well as environmental factors but their arrangement and management determine the photosynthetic efficiency of the whole plant-community (Nair, 1993). However, photosynthetic pathways are useful when choosing crop species e.g. in permanent woody overstory systems with $C_{3}$ trees; $C_{3}$ crops are preferred (legumes, potatoes, most trees etc.) as they have a greater efficiency of $\mathrm{CO}_{2}$ uptake at lower irradiance levels than $\mathrm{C}_{4}$ plants (Tieszen, 1983). The outputs from the interactions between trees and crops cannot easily be predicted as the interactions are influenced by many factors including environmental conditions and plant species (Sheley and James, 2014). Therefore, more research is needed to screen more crop varieties for their specific responses, and to understand the mechanisms of such responses under Eucalyptus trees canopies for easy management practices to cope with the dynamics of water and soil fertility coupled with allelopathic effects.

The aim of this study was to establish and assess the performance of farm crops under Eucalyptus trees (plantations) so as to evaluate the potential of the tree for agroforestry. The assessment of the performance of the crops was mainly on; germination, growth rates and possible yield potentials. In addition, the canopy analysis in terms of light resource capture by measuring the photosynthetically active radiations (PAR) reaching the crops and understory crop leaf area index (LAI).

\section{Results}

\section{Germination of crops under Eucalyptus grandis tree canopies}

Cumulative germination of crops under trees and in the open field was statistically different $(p=.05)$. The mean germination for beans was $73 \%$ (6 year old plantation), and $94 \%$ ( 3 year old plantation) while $84 \%$ for the open field. The mean germination for potatoes was $77 \%$ (6 year old plantation), 93\% (3 year old plantation) and 91\% for open field (Fig $1 \& 2$ ). Survival rate for nightshade 14 days after planting was $100 \%$ under the canopy while $95 \%$ in the open field with statistically significant differences between canopy and open field ( $p=.05$ ) ( Fig 3). The number of days elapsed before onset of germination was more than twice for crops inside the tree plantations when compared to crops in the open field with potatoes taking 4 days to germinate under open field while more than 8 days under the canopy (Fig 1). Beans took 2 days under open field and more than 4 days under the canopy (Fig 2). The effect of season on the germination of beans and Irish potatoes was statistically significant $(p<.001)$ both recording higher percentages in the second season.

\section{Leaf Area Index (LAI) of the understory crops}

The age difference in tree plantations significantly affected the LAl of the understory crops

$(p<.001)$. The age difference in the plantations had a statistically significant effect on the LAl of potatoes and beans with 6 year old canopy $(1.39,1.54)$ having a bigger effect on LAl compared to 3 year old $(1.09,0.93)$ respectively. The LAI of nightshade was not affected by the age of the plantation (Table 4; Fig 4). In addition, LAI values of potatoes and beans grown in the open field were higher and significantly different from those under the tree canopies; however for nightshade vegetable, there was no significant difference. Pruning of the base canopy branches significantly increased the LAI for beans and potatoes but not for the nightshade, Table 4. Seasonal variations affected the LAl of nightshade significantly but not for beans and potatoes. Generally, the LAI was higher in potatoes and beans compared to nightshade (Table 4; Fig 4, 5, 6, 7 \& 8).

\section{Yield of the understory crops}

The yields of crops grown inside the Eucalyptus plantations and those in the open field were statistically different for beans and potatoes $(p<.001)$ but not for nightshade vegetable. For beans and potatoes, plantation age differences and pruning of base canopy branches had no significant effect on yield (Table 5). Furthermore, yields of beans in the open field were two times more compared to that grown inside the plantation. The fertilized beans in the open field produced the highest yields $(0.49 \mathrm{t} / \mathrm{ha})$, followed by pruned plantation aged 3 years $(0.27 \mathrm{t} / \mathrm{ha}), 6$ year old tree canopy $(0.25 \mathrm{t} / \mathrm{ha})$ and lastly was the un-fertilized beans in the open field ( $0.23 \mathrm{t} / \mathrm{ha}$ ). Yield production for potatoes had the same trend as beans, whereby the fertilized open field was twice that of under tree canopy plantations. For nightshade vegetable, the yields from the fertilized open fields were not statistically different from those under the tree canopy plantations. Pruning of the Eucalyptus tree canopies had no significant change on yields of the nightshade. Seasonal variations did not have a significant change on the yields of the tested crops. The age of the Eucalyptus plantation had a significant effect on the yields of nightshade with a 3 year old canopy giving a higher yield compared to a 6 year old for two consecutive seasons. The yields of tested crops were positively and significantly correlated to LAI and PAR (Table 6). The strength of the linear relationship between yield and LAI was stronger in potatoes $(r=.74)$ followed by beans $r=.64$ and weaker in nightshade (Table 6). Multiple regression analysis was performed using yield as the dependent variable while PAR and LAI as the independent or predictor variables in the model. Linear regression relationships seemed to be appropriate 
Table 1. Mean monthly soil, air temperatures and rainfall during the cropping period

\begin{tabular}{lcc|ccc}
\hline & Under trees & \multicolumn{4}{c}{ Open field } \\
& Air temp & Soil temp & Air temp & Soil temp & Rainfall (mm) \\
\hline Season 1: 2015 & Mean & Mean & Mean & Mean & Mean \\
NOV & 18 & 12 & 22 & 16 & 100 \\
DEC & 21 & 15 & 24 & 17 & 81 \\
2016 & & & & & \\
JAN & 22 & 15 & 24 & 16 & 40 \\
FEB & 24 & 17 & 27 & 20 & 20 \\
Season 2: 2016 & & & & & \\
MAY & 19 & 14 & 21 & 15 & 90 \\
JUNE & 18 & 14 & 18 & 14 & 40 \\
JULY & 16 & 15 & 18 & 15 & 20 \\
AUG & 21 & 19 & 24 & 22 & 0 \\
\hline
\end{tabular}

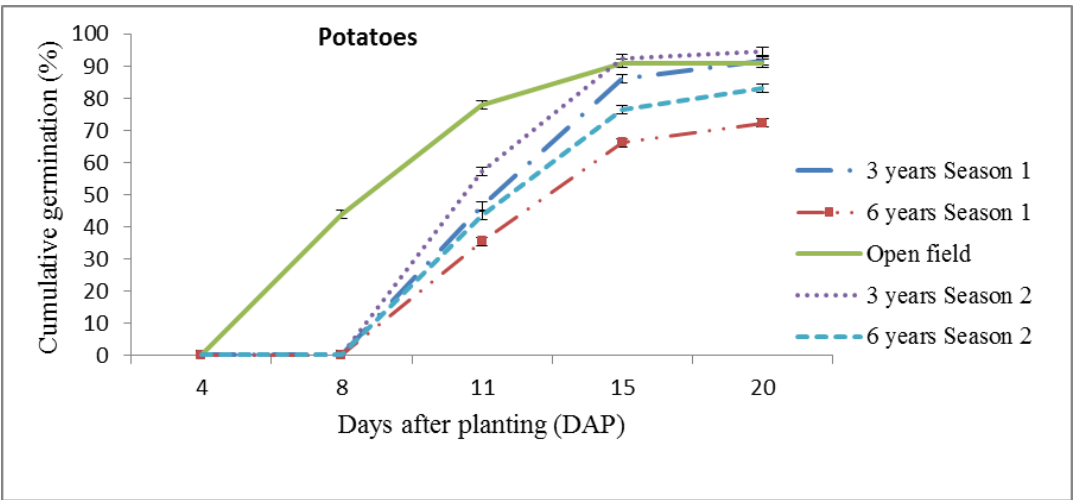

Fig 1. Cumulative germination (\%) in Irish potatoes under Eucalyptus grandis tree plantations of different ages.

Table 2. Soil characteristics under 3 and 6 year old Eucalyptus tree canopies (0-20 cm depth).

\begin{tabular}{lccc}
\hline Parameter & 3 year old canopy & 6 year old canopy & Open field (fallow) \\
\hline Chemical parameters & & & \\
pH (1:2.5) & 5.7 & 5.8 & 5.9 \\
Available phosphorus (ppm) & 3.3 & 3.8 & 9 \\
Total phosphorus (ppm) & 396 & 721 & 141 \\
Total Nitrogen (TN \%) & 0.26 & 0.28 & 0.13 \\
Organic Matter (OM \%) & 3.5 & 3.6 & 3.1 \\
Calcium (mg/ kg) & 1192 & 1053 & 712 \\
Magnesium (mg/ kg) & 457 & 470 & 268 \\
Potassium (mg/ kg) & 456 & 387 & 211 \\
Manganese (mg/ kg) & 1020 & 941 & 792 \\
Iron (mg/ kg) & 537 & 847 & 741 \\
physical parameters & & & \\
Bulk density (g/cm ${ }^{3}$ ) & 0.94 & 0.92 & 1.2 \\
Moisture content (\%) & $29-35$ & $30-35$ & 32 \\
Field capacity v/v & 55 & 57 & 51 \\
Texture grade & clay loam & clay loam & clay loam \\
\hline
\end{tabular}

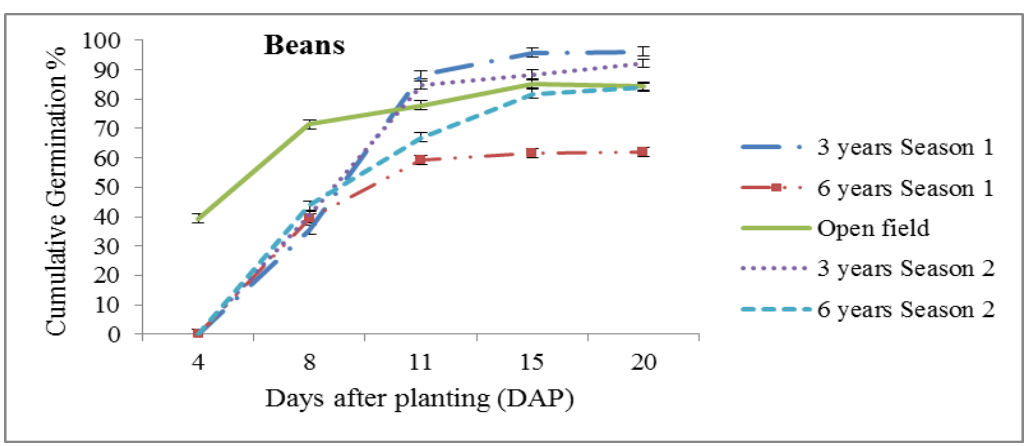

Fig 2. Cumulative germination (\%) in common beans under Eucalyptus grandis tree plantations of different ages. 
Table 3. PAR measurements under Eucalyptus tree plantations of different ages $\left(\mu \mathrm{mols}^{-1} \mathrm{~m}^{-2}\right)$.

\begin{tabular}{lccc}
\hline Plantation age & Potatoes & Beans & Nightshade \\
\hline Plantation of 3 years: season 1 & $30.65 \mathrm{a}$ & $31.64 \mathrm{a}$ & $31.45 \mathrm{a}$ \\
Pruned plantation of 3 years: Season 1 & $142.43 \mathrm{~b}$ & $70.01 \mathrm{~b}$ & $81.09 \mathrm{~b}$ \\
Plantation of 6 years: season 1 & $37.23 \mathrm{ab}$ & $36.41 \mathrm{ab}$ & $38.08 \mathrm{ab}$ \\
Plantation of 6 years: season 2 & $88.20 \mathrm{~b}$ & $64.57 \mathrm{~b}$ & $82.32 \mathrm{~b}$ \\
Control/Open field & $849.10 \mathrm{c}$ & $848.60 \mathrm{c}$ & $769.50 \mathrm{c}$ \\
\hline $\mathrm{CV}(\%)$ & 10.92 & 15.3 & 23.10 \\
$\mathrm{LSD}_{(p=.05)}$ & 39.45 & 17.00 & 25.50 \\
\hline
\end{tabular}

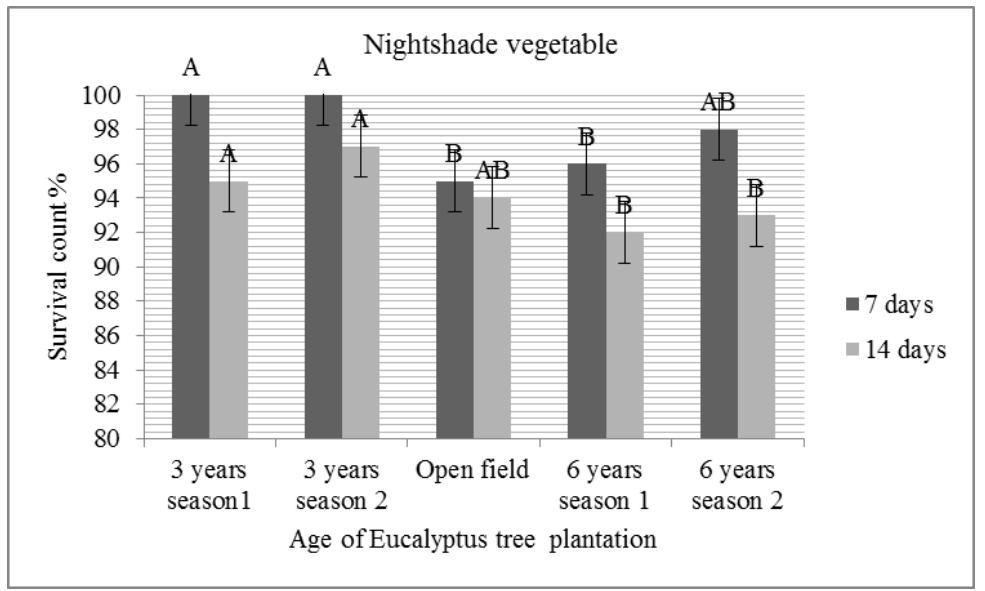

Fig 3. Survival count (\%) of nightshade vegetable under Eucalyptus grandis tree plantations of different ages. A mean value followed by the same letter on bars do not differ significantly from each other at 5\% level of significance according to Tukey's HSD Test.

Table 4. Leaf Area Index (LAI) of the tested crops under Eucalyptus canopies of different ages.

\begin{tabular}{lccc}
\hline Plantation age & Potatoes & Beans & Nightshade \\
\hline Control/Un-Fertilized open field & $1.12 \mathrm{a}$ & $1.04 \mathrm{a}$ & $0.70 \mathrm{a}$ \\
Plantation of 3 years: season 1 & $1.09 \mathrm{a}$ & $0.93 \mathrm{a}$ & $0.90 \mathrm{~b}$ \\
Pruned plantation of 3 years & $1.67 \mathrm{~b}$ & $1.20 \mathrm{~b}$ & $0.74 \mathrm{a}$ \\
Plantation of 6 years: season 1: Season 1 & $1.36 \mathrm{c}$ & $1.39 \mathrm{bc}$ & $0.89 \mathrm{~b}$ \\
Plantation of 6 years: season 2 & $1.39 \mathrm{c}$ & $1.54 \mathrm{c}$ & $0.61 \mathrm{c}$ \\
Open field & $2.65 \mathrm{~d}$ & $2.36 \mathrm{~d}$ & $1.16 \mathrm{~d}$ \\
\hline $\mathrm{CV}(\%)$ & 24.10 & 28.70 & 23.10 \\
$\mathrm{LSD}$ & 0.21 & 0.24 & 0.30 \\
\hline
\end{tabular}

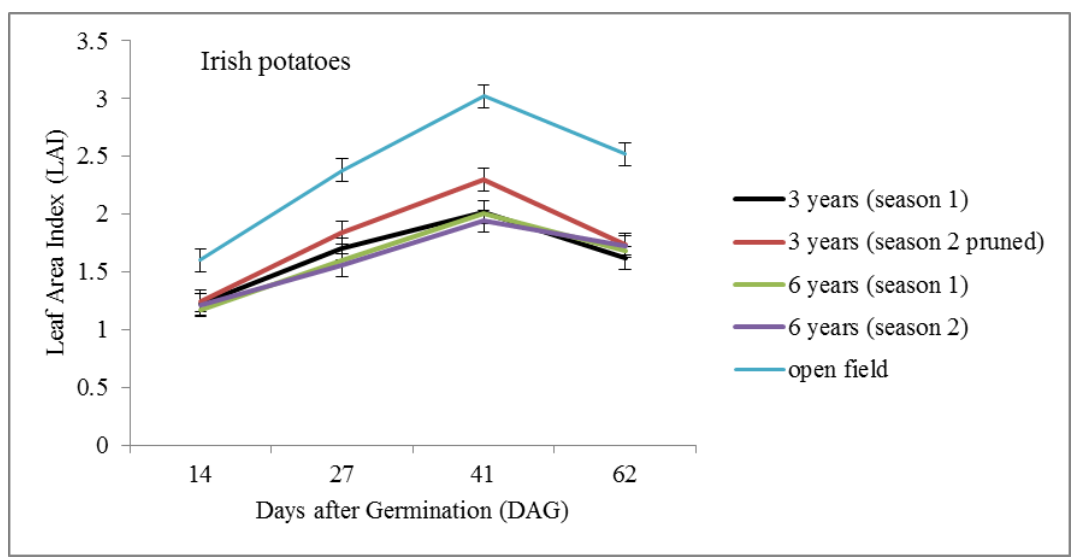

Fig 4. LAI measurements for Irish potatoes during the growing period under Eucalyptus plantations of different ages. 
Table 5. Yield of field crops under Eucalyptus grandis tree canopies of different ages.

\begin{tabular}{|c|c|c|c|}
\hline Canopy & Potatoes (t/ha) & Beans (t/ha) & Nightshade (t/ha) \\
\hline Control/Un-Fertilized open field & $4.63 a$ & $0.23 a$ & $0.17 a$ \\
\hline Plantation of 3 years: season 1 & $5.31 \mathrm{ab}$ & $0.22 a$ & $0.29 b$ \\
\hline Pruned plantation of 3 years: Season 1 & $5.77 b$ & $0.27 a$ & $0.32 b$ \\
\hline Plantation of 6 years: season 1 & $5.14 a b$ & $0.22 a$ & $0.22 c$ \\
\hline Plantation of 6 years: season 2 & $5.12 \mathrm{ab}$ & $0.25 a$ & $0.21 \mathrm{ac}$ \\
\hline Open field (Fertilized) & $9.61 \mathrm{c}$ & $0.49 a$ & $0.29 b$ \\
\hline CV (\%) & 10.30 & 31.40 & 13.50 \\
\hline $\operatorname{LSD}_{(p=.05)}$ & 1.21 & 0.44 & 0.08 \\
\hline
\end{tabular}

A mean value followed by the same letter do not differ significantly from each other at $5 \%$ level of significance according to Tukey's HSD Test.

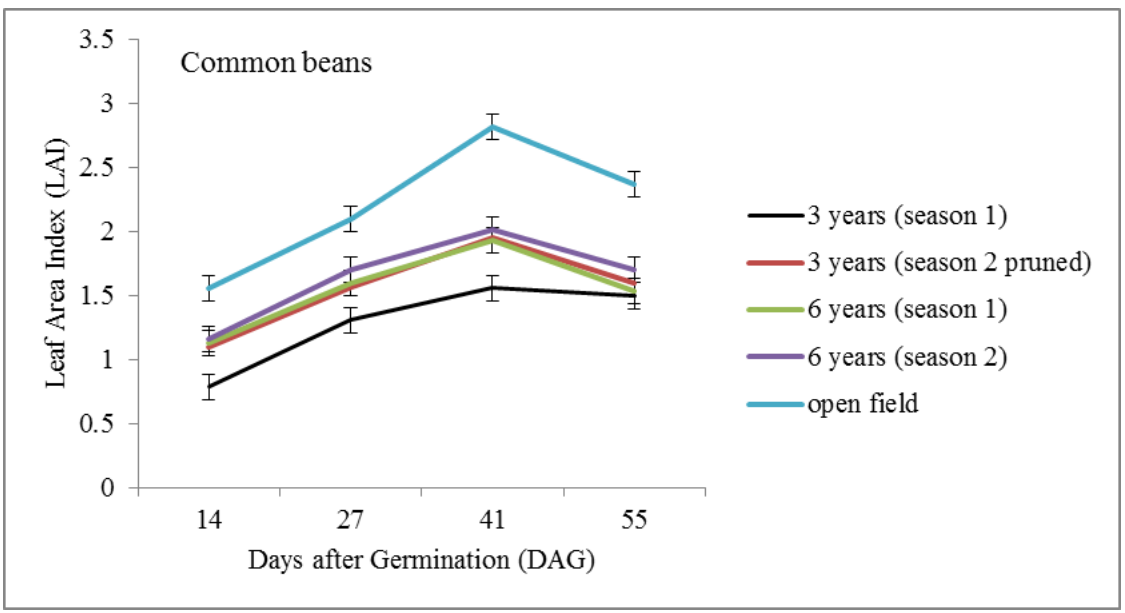

Fig 5. LAl measurements for beans during the growing period under Eucalyptus plantations of different ages.

Table 6. Pearson Correlation coefficients: beans, potatoes and nightshade under Eucalyptus trees.

\begin{tabular}{|c|c|c|c|c|c|c|c|c|c|}
\hline & \multicolumn{3}{|l|}{ Beans } & \multicolumn{3}{|c|}{ Irish potatoes } & \multirow{2}{*}{$\frac{\text { Nightshade }}{\text { Yield }}$} & \multicolumn{2}{|l|}{ vegetable } \\
\hline & Yield & LAI & PAR & Yield & LAI & PAR & & LAI & PAR \\
\hline Yield & 1 & $0.64 * *$ & $0.56 * *$ & 1 & $0.74 * *$ & $0.67 * *$ & 1 & $0.23 * *$ & $0.20 * *$ \\
\hline LAI & $0.64 * *$ & 1 & $0.51 * *$ & $0.74 * *$ & 1 & $0.57 * *$ & $0.23 * *$ & 1 & $0.41 * *$ \\
\hline PAR & $0.55^{* *}$ & $0.51 * *$ & 1 & $0.67 * *$ & $0.57 * *$ & 1 & $0.20 * *$ & $0.41 * *$ & 1 \\
\hline
\end{tabular}

**Correlation is significant at the 0.01 level (2-tailed); ${ }^{*}$ Correlation is significant at the 0.05 level (2-tailed).

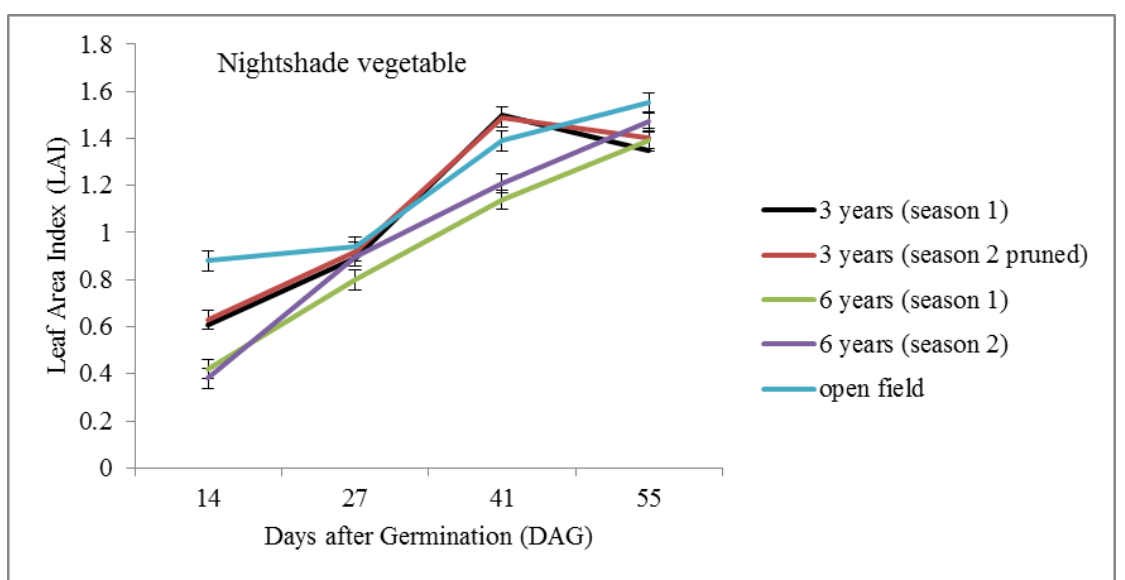

Fig 6. LAI measurements for Nightshade vegetable during the growing period under Eucalyptus plantations of different ages. 


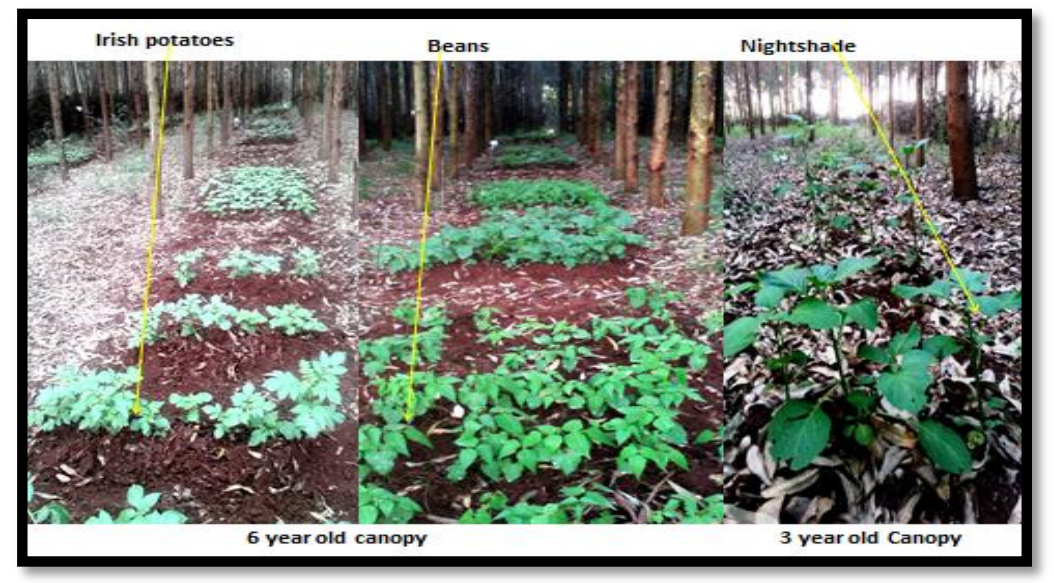

Fig 7. Performance of crops under 3 and 6 year old Eucalyptus tree plantations, season 1.

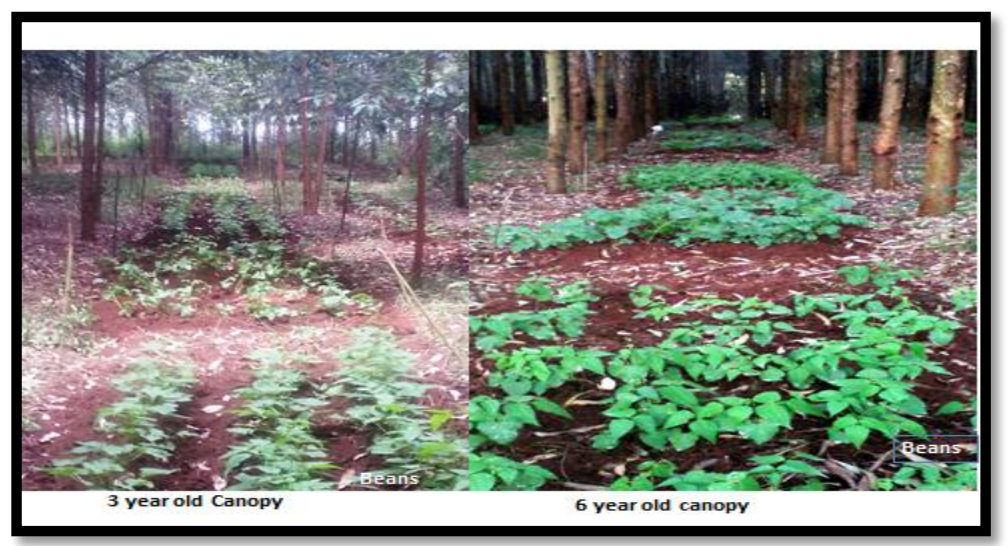

Fig 8. Performance of crops under 3 and 6 year old Eucalyptus tree plantations, season 2.

models having higher $r^{2}$ values for beans and potatoes but not nightshade. From the results, all the predictors were significant statistically. For beans, the $r^{2}=.48$, meaning approximately $48 \%$ of the variance in yield was accounted for by the model, in this case, the two predictors (LAl and PAR). Linear equations for each variables/ predictors were developed;

Yield $(\mathrm{kg})=.088+7.281 \mathrm{E}-5[\mathrm{PAR}]+.088[\mathrm{LAl}], r^{2}=.48 \quad p$ $<.001$

Yield $(\mathrm{kg})=0.212+0.00[\mathrm{PAR}], r^{2}=.31 \quad p<.001$

Yield $(\mathrm{kg})=0.064+0.116\left[\right.$ LAl], $r^{2}=.41 \quad p<.001$

For potatoes, the $r^{2}=.64$, meaning $64 \%$ of the variance in yield was accounted for by the model, in this case, the two predictors (LAI and PAR).

Yield $\left.\left.(\mathrm{kg})=2.71+.001[\mathrm{PAR}]+1.21[\mathrm{LAl}], r^{2}=.64\right) \quad p<.001\right)$

Yield $\left.\left.(\mathrm{kg})=4.49+0.002[\mathrm{PAR}], r^{2}=.45\right) \quad p<.001\right)$

Yield $(\mathrm{kg})=2.22+1.70\left[\right.$ LAl], $\left.\left.r^{2}=.55\right) p<.001\right)$

For nightshade vegetable, the coefficients for PAR and LAI were positive PAR $(b=.005))$ but not significant $(p=0.09)$, indicating that increase in PAR under the tree canopy did not necessarily increase yield. The $r^{2}=.065$ meant approximately $1 \%$ of the variance in yield was accounted for by the model hence linear regression relationships seemed not appropriate in this case. Linear equations for each variables/ predictors were developed;

Yield $(\mathrm{kg})=0.19+.005[\mathrm{PAR}]+9.305[\mathrm{LAl}], r^{2}=.065, p<.001$

Yield $(\mathrm{kg})=0.21+0.007[\mathrm{PAR}], r^{2}=.04, p<.05$
Yield $(\mathrm{kg})=0.81+12.55[\mathrm{LAI}], r^{2}=0.05, p<0.001$

\section{Photosynthetically active radiation (PAR) reaching understory crops}

In this study, the amount of photosynthetically active radiation (PAR) reaching the crops under the tree canopy was many times less and statistically different from that recorded in the open field $(p<.001)$. On average, The PAR recorded in the open field was as expected many times compared to that recorded under canopy with potatoes $\left(849.1 \mu \mathrm{mols}^{-1} \mathrm{~m}^{-2}\right.$ ) beans $\left(848.6 \mu \mathrm{mols}^{-1} \mathrm{~m}^{-2}\right)$ nightshade (769.5 $\mu_{\mathrm{mols}^{-1}} \mathrm{~m}^{-2}$ ) (Table 3). The maximum PAR recorded in the open field was $1881 \mathrm{\mu mols}^{-1} \mathrm{~m}^{-2}$ (February) and minimum $67.3 \mu_{\mathrm{mols}}^{-1} \mathrm{~m}^{-2}$ (June) 2016. Pruning of the canopy increased the amount of PAR and it was statistically significant $(p<.001)$. Seasonal variations significantly affected the amount of PAR reaching the crops (Table 3 ). The age difference in the plantations had no significant effect on the PAR reaching the crops.

\section{Discussion}

The amount of solar radiation intercepted by a canopy is dictated by many factors including; the leaf angle, size, shape and even the thickness, which together with its chlorophyll concentration are key determinants (Campillo et al., 2012). In this study, the age differences in the Eucalyptus tree plantations had no significant effect on the amount of 
PAR reaching the understory crops but as expected pruning of the canopy base branches significantly increased the amount of PAR reaching the understory. Seasonal variations in weather conditions significantly affected the amount of PAR reaching the understory crops. The effect of the amount of PAR reaching the understory on the LAI and the yields of crops was stronger in potatoes and beans. It is believed that only $50 \%$ of the incident radiation intercepted by plant canopy is utilized for photosynthesis (Loomis and Connor, 2002; Varlet-Gancher et al., 1993). Maximum productivity in crop canopies depends on the capture of incident solar radiation which is influenced by optimal levels of water and nutrients (Loomis and Connor, 2002) in this case from soils under the Eucalyptus tree canopy. For instance, the availability of soil nitrogen has been reported to influence the efficiency of radiation interception by a canopy (ScottGreen et al., 2003). Leaf Area index (LAI) has been defined from literature as the area of green leaves per unit area of the ground (Jonckheere et al., 2004) and it is affected by many factors including the species type, stage of growth, management practices etc. In this study, leaf area index (LAI) of the understory crops was significantly affected by shade of Eucalyptus tree canopies of different ages. In addition, LAl of potatoes and beans grown in the open field was higher and significantly different from crops grown under trees but the difference was minimal for nightshade. Pruning of the Eucalyptus tree canopy branches significantly increased the LAI of beans and potatoes but not of nightshade. Seasonal variations significantly affected the LAI of nightshade but not of beans and potatoes. Generally, the LAI was higher in potatoes and beans compared to nightshade with 6 year old tree canopy having a bigger effect on LAl compared to 3 year old, a fact contributed by more PAR recorded under 6 year old tree canopy and perhaps due to differences in the crop species. In fact from literature, LAl of Irish potatoes have been known to be influenced by the cultivar planted and even water stress (Gordon et al., 1997) with maximum LAl values of 2-4 recorded for different cultivars. In Soybean, soil type is reported to influence the LAl and yield (Jones, 2002). Similar results have been reported by Deshi et al., (2015) with optimum and minimum LAI values of 3.45 and 2.16, respectively for different varieties of Irish potatoes planted in open field. In addition, Soybean grown in open fields, have recorded LAl values of 3.5 to 4 (Jones, 2002). Most annual crops grown in the open field have recorded maximum LAl values of between 2 and 4 while for trees, maximum values of 8 have been observed for deciduous forests (Beadle, 1993) and these agrees with the findings in this study where the age difference in the tree had a huge significant difference on the LAI of potatoes and beans. High values of LAI in plants have been linked to better performance of the plant canopy (Boken and Chandra, 2012) with the concept of leaf area index (LAI) being proposed to be used as an estimator of the crop's ability to capture the light energy available for plant growth (Campillo et al., 2012). Plant canopy photosynthetic rates have been shown to increase as leaf area increases (Westgate, 1999). A number of studies have concluded that the maximum rate of canopy photosynthesis occurs when about $90-95 \%$ of available solar radiation is intercepted by the canopy (Westgate, 1999). For example, in late-planted soybean, increasing leaf area to maximize light interception (LI) has been deemed important for increased biomass often associated with higher yields (Wells, 1991).

The tested crops grown under Eucalyptus trees had significantly higher yields compared to the un-fertilized crops in open field which was explained by the simple fact that the soils under the canopy were rich in plant nutrients from litter mineralization. The yields of beans were way below those reported by KALRO (KARI, 2008) of the tested variety when planted in the open field of 1.8-2.0 t/ha and even below the national production of common beans in 2013 which was $0.5 \mathrm{MT} / \mathrm{ha}$ (USAID, 2016). Just like beans, there was no significant difference in potato yields across the tree plantations of different ages. The potato yields were also below those reported by KARI Report, (2008) when the variety was released whereby; yields ranged between 35-45 $\mathrm{t} / \mathrm{ha}$ when planted in the open field. Furthermore, the potato yields were below those of national production of 2014 which was 13.4 MT/ha (USAID, 2014). For nightshade vegetable, yields under fertilized open field were not significantly different from those under trees. Compared to national production of $7.5 \mathrm{MT} / \mathrm{ha}$ (2014) and $9.9 \mathrm{MT} / \mathrm{ha}$ (2013) (USAID, 2014), the nightshade yields were low and this could be due to a number of factors ranging from the variety, spacing, fertilization and the mode of establishment. The yields of tested crops were positively and significantly correlated to LAI and PAR but the strength of the linear relationship between yield and LAI was stronger in potatoes and beans but weaker in nightshade. Therefore, to fully model the effect of PAR on LAl and yield in nightshade vegetable, then models like polynomial regression forms of linear regression or hyperbolic function models should be used as such models have been fully utilized in bioscience studies elsewhere. Nightshade vegetable performed better under the tree canopy (inside the plantations) compared to beans and potatoes, producing yields not significantly different as when grown and fertilized in the open field. This was attributed to many factors with key among them being that nightshade as one of the $C_{3}$ photosynthetic pathway plant, perhaps utilized light more efficiently therefore performing better under reduced solar radiation. From literature, it has been suggested by Nair, (1993) and Tieszen, (1983), that for annual or seasonal type of agroforestry such as cropping under Eucalyptus, then it is suggested that understory plants should be able to build up leaf area as quickly as possible so as to compete well with the over-story plants. In conditions with a permanent woody over-story like in this study growing under Eucalyptus trees, where the trees possess the $C_{3}$ pathway; then under-story plants should be $\mathrm{C}_{3}$ crops (Tieszen, (1983) hence the choice of tested crops including nightshade in this study. For increased crop production under the Eucalyptus tree canopies, management strategies should be geared towards increasing or maximizing the penetration of solar radiation to reach the understory crops. In addition, the crop species that thrive better under low levels of PAR like in this scenario the nightshade should be selected. Such strategies include tree management practices like spacing and pruning of branches. Other important factors to consider are; water availability to crops, providing deficient soil nutrients and allelopathy. 


\section{Materials and methods}

\section{Study area}

The experiments were conducted between in between 2015 and 2016 at Kenya Forestry Research institute (KEFRI) Muguga, Kenya (latitude $1^{\circ} 15^{\prime} 0^{\prime \prime} S$ and longitude $36^{\circ} 40^{\prime}$ 0 "E). The area averages rainfall of $900-1200 \mathrm{~mm}$ p.a. at an elevation of $2040 \mathrm{~m}$ above sea level. The soils have moderate to high fertility with a $\mathrm{pH}$ of 5.8 and are classified as Eutric Nitisols (WRB, 2006).

\section{Soil characterization and weather patterns during the study period}

The soil chemical and physical parameters under the Eucalyptus tree canopies and the open field differed greatly. The content of available phosphorus was marginally lower inside the plantations than the open field. However, total phosphorus under trees was many times higher than in the open field. The exchangeable bases (cations) were very high under the canopies than in the open field. Soils in the open field had a higher bulk density but lower field capacity moisture levels. Both soils under the canopies and the open field had clay-loam texture grades (Table 1). For weather conditions, Season 1 received more rainfall than season 2 which was characterized by low temperatures and dense cloud cover for most of the cropping period. The temperatures in the open field were slightly higher than under the tree canopy (Table 2).

\section{Planting of crops under Eucalyptus tree canopies/ Plantations}

Farm crops i.e. Irish potatoes (Solanum tuberosum L.), Common beans (Phaseolus vulgaris), a grain legume and the Black Night shade vegetable (Solanum villosum) were planted inside pure stands of Eucalyptus grandis plantations of ages 3 and 6 years. These farm crops were selected because of their popularity as the main crops grown in the study area: There was no undergrowth except for scattered grasses inside the plantations. The crops were planted along the rows of Eucalyptus in plot sizes of $4 \mathrm{~m}$ by $2 \mathrm{~m}$. Since tree spacing was $4 \mathrm{~m}$ by $3 \mathrm{~m}$ then minimum tree-crop distance was $0.5 \mathrm{~m}$ while $1.5 \mathrm{~m}$ the maximum. The experimental design was a factorial arrangement in Randomized complete block design (RCBD) with three replicates. Crop spacing for potatoes was $45 \mathrm{~cm}$ by $30 \mathrm{~cm}$; common beans $30 \mathrm{~cm}$ by 15 $\mathrm{cm}$ and $40 \mathrm{~cm}$ by $15 \mathrm{~cm}$ for the night shade vegetable. The seeds for common beans and black night shade were sourced from the local agro-vets while for the potatoes was sourced from Kenya Agricultural and Livestock Research Organization ( KALRO) Tigoni Gene bank Centre. A similar experiment to this was set up in the open field in the same location on land left fallow for one year previously cropped with maize and beans after harvesting of mature Eucalyptus grandis trees 3 years earlier for comparison purposes. For the experiment in the open field, inorganic fertilizer NPK (17:17:0) was applied during planting with control no having fertilizer applied. For the experiment under tree canopy, no fertilizer was applied.
Measurement of Germination, Leaf area index (LAI), Yield and Photosynthetically active radiation (PAR)

The following crop data was collected; cumulative germination percentage, Leaf area index (LAI) and the yields. The photosynthetically active radiation (PAR) reaching the understory crops was also recorded. In this study a portable Light meter (LI-COR Model LI-189) attached to a radiation Quantum sensor was used to measure PAR (LI-COR, 1995). The sensor was exposed to the sky at $0.5 \mathrm{~m}$ distance over the crops and the measurements of PAR done instantaneously. Measurements per plot consisted of 3 recordings done systematically (middle and at the edges) inside the crop plots. The PAR measurements were carried out on a weekly basis starting after full germination of the crops mostly at midday when the sun was directly overhead. For the leaf area index measurements, a plant canopy analyzer equipment (LI-COR Model: LAI-2000) was used to measure and compute the amount of foliage of the understory crops using the LAI-2050 optical sensor attached to it (LI-COR, 1992). Since the crops were planted in rows then the readings were made along diagonal transects between the rows but at even intervals across the row so as to improve the spatial average. Two (2) above canopy readings were made with each having four (4) below canopy readings (one above canopy reading was followed by four (4) below canopy readings for one complete set of measurement per plot). Leaf area index was measured at the same geo-referenced points in crop plots. The LAI measurements were carried out on a fortnight (14 days) basis starting 1 month after emergence of the crops up to harvest maturity. The measurements were done at sunrise, sunset or using a 270 degree view cap to avoid direct sunlight. Measurement of the crop yield was done at harvest maturity from the experimental plots $(4 \mathrm{~m}$ by $2 \mathrm{~m})$. For common beans, dry kernel weights were measured (moisture content of 13\%); fresh leaf weight was measured for nightshade while fresh tuber weight was measured for Irish potatoes.

\section{Statistical data analysis}

Data analysis involved analysis of variance to ascertain the effects of the plantation canopy and its age on crop performance and canopy attributes (PAR). Multiple comparisons and Mean separation were done with Least Significance Difference (LSD) and Tukey's HSD tests using GenStat Edition 16 (VSN International, 2013) statistical software. Correlations of LAI and PAR and yields were done using Pearson's method with two tailed T-test. In addition, multiple regression was done to model yield, LAI and PAR relationships using IBM SPSS Statistics Version 23 formerly SPSS (IBM Corp, 2016).

\section{Conclusion}

The performance of beans, potatoes and nightshade under Eucalypts tree canopies of different ages was successful. Germination of crops under trees was marginally higher than in the open field i.e. the 3 year old plantations (94\%, 93\%) gave a higher germination for beans and potatoes than when planted in the open field $(84 \%, 91 \%)$ respectively. The survival rate for nightshade was $100 \%$ under trees while 95 
$\%$ in the open field. Germination rate was low or delayed under trees as crop seeds took more time to emerge as compared to when planted in the open field. Germination of beans and Irish potatoes improved with the cropping seasons.

The age differences in the Eucalyptus tree plantations had no significant effect on the amount of PAR reaching the understory crops. The leaf area index (LAI) of the understory crops was significantly affected by Eucalyptus trees of different ages. The effect of Eucalyptus plantation age significantly affected the yields of beans and potatoes but not nightshade. The crops grown under Eucalyptus trees gave significantly higher yields compared to crops grown in open fields but which were not fertilized. Since the yields for nightshade vegetable grown in the open and fertilized fields were not significantly different from those under trees, therefore, the vegetable can be grown under Eucalyptus canopy/shade without reduction in yield. Irish potato and common bean are potential crops for agroforestry with Eucalyptus trees but need further research as their yields were low and had selected disease incidences.

\section{Acknowledgments}

I acknowledge the staff at Kenya Forestry Research Institute (KEFRI) Forest management section at Muguga for their support in setting up the trials and allowing us to use their plantations for this study

\section{References}

Beadle CL (1993) Growth Analysis. In: Hall DO et al., (Eds). Photosynthesis and production in a changing Environment: A field and laboratory manual. Chapman and Hall, London. Pp 36-46.

Boken K, Chandra S (2012) Estimating leaf area index for an arid region using spectral data. Afr Crop Sci J. 20(4): 215223.

Campillo C, Fortes R, Prieto HM (2012) Solar radiation effect on crop production, Solar radiation, Prof. Elisha B. Babatunde (Ed.), ISBN: 978-953-51-0384-4, InTech, Europe University Campus. Croatia. Retrieved January, 2017, from http://www.intechopen.com/books/solar-radiation/solarradiation-effect-on-crop-production

Deshi KE, Obasi MO, Odiaka NI, Kalu BA, Ifenkwe OP (2015) Leaf area index values of potato (Solanum tuberosum L.) stored for different periods in different kinds of stores. IOSR-JAVS. 8: (1) 09-19.

Dhillon RS, Bhardwaj KK, Beniwal RS, Bangarwa KS, Kumari S, Godara AS, Sheokand RN (2016) Performance of wheat as intercrop under different spacings of poplar plantations in semiarid ecosystem of northern India. Indian J Ecology. 43: 323-327.

FAO (2006) World agriculture: towards $2030 / 2050$ prospects for food, nutrition, agriculture and major commodity groups. Rome.

Gordon R, Brown DM, Dixon MA (1997) Estimating potato leaf area index for specific cultivars. Potato Res. 40: 251256. Kluwer Academic Publishers.

IBM Corp. Released (2016) IBM SPSS Statistics for Windows, Version 23.0. Armonk, New York: IBM Corp

IUSS Working Group. WRB (2006) World reference base for soil resources 2006. A framework for International classification, correlation and communication. World Soil Resources Report No 103. FAO, Rome

Johar V, Dhillon R.S, Bhardwaj K.K, Bisht V, Kumar T (2017) Effect of light intensity on yield of wheat under Eucalyptus tereticornis based agri-silvi-horticultural system. Hisar-125 004, India. Indian J Ecology. 44 (Special Issue-4).

Jonckheere I, Fleck S, Nackerts K, Muys B, Coppin P, Baref M (2004) Review of methods for in situ leaf area index determination: theories, sensors and hemispheral photography. Agric For Meteorol. 121(1-2):19-35.

Jones BP, (2002) Determination and manipulation of leaf area index to facilitate site-specific management of double-crop soybean in the mid-Atlantic, U.S.A. M.S. Thesis. Virginia Polytechnic Institute \& State University, Blacksburg, VA

Kenya Agricultural Research Institute, KARI (2008) Grow Improved beans. In: Karanja et al., (2008) KARI information brochure series. Nairobi. Retrieved January, 2017, from www.kalro.org/fileadmin/publications/brochuresll/Grow improved beans.pdf

Kenya Forest Service (2009) A guide to on-farm Eucalyptus growing in Kenya. Kenya Forest Services, Ministry of Forestry and Wildlife, Kenya

Licker R, Johnston M, Foley JA, Barford C, Kucharik CJ, Monfreda C, Ramankutty N (2010) Mind the gap: how do climate and agricultural management explain the 'yield gap' of croplands around the world? Glob Ecol Biogeogr. 19:769-782.

LI-COR (1992) LAI-2000 Plant canopy analyzer instruction manual. Lincoln, Nebraska U.S.A. Retrieved December, 2015, from http://www.vtpup.cz/common/manual/PrF biofyz LICOR LI189 manual EN.pdf

LI-COR (1995) LI-189 Quantum/Radiometer/Photometer operating manual. Lincoln, Nebraska U.S.A. Retrieved January, 2016, from www.vtpup.cz/common/manual/PrF biofyz LI COR LI189 manual EN.pdf

Loomis RS, Connor DJ (2002) Crop Ecology: Productivity and management in agricultural system. Cambridge University press

Mugunga CP (2016) The use of Eucalyptus in agroforestry systems of southern Rwanda: to integrate or segregate? PhD thesis, Wageningen University, Wageningen. 162 pages ISBN: 978-94-6257-753-4 DOI: http://dx.doi.org/10.18174/375484

Nair PKR (1993) An Introduction to Agroforestry. University of Florida, Kluwer Academic Publishers. Gainesville, Florida, U.S.A

Oballa PO, Konuche PKA, Muchiri MN, Kigomo BN (2010) Facts on growing and use of Eucalyptus in Kenya. Nairobi. Kenya Forestry Research Institute (KEFRI) publication

Sasikumar K, Vijayalakshmi C, Parthiban KT (2002) Allelopathic effects of Eucalyptus on blackgram (Phaseolus mungo L.). Allelopathy J. 9: 205-214.

Scott-Green D, Erickson JE, Kruger EL (2003) Foliar morphology and canopy nitrogen as predictors of light-use efficiency in terrestrial vegetation. Agric For Meteorol. 115:163-171. Elsevier Science B.V.

Sheley RR, James JJ (2014) Simultaneous intraspecific facilitation and interspecific competition between native and annual grasses. J Arid Environ. 104: 80-87. 
Tieszen LL (1983) Photosynthetic systems: implications for agroforestry. In: Huxley, P.A. (ed.), Plant Research and Agroforestry. Pp 365-378. ICRAF, Nairobi. Kenya.

USAID (2014) Horticulture validated report. Retrieved April, 2017,

from

http://www.agricultureauthority.go.ke/wpcontent/upload s/2016/05/HorticultureValidated-Report-2014-Final-

copy.pdf

USAID (2016) Kenya early generation seed study country report. Early generation seed systems study, feed the future: Building capacity for African agricultural transformation (Africa Lead II). Retrieved April, 2017, from http://www.africaleadftf.org/wp-

content/uploads/2016/09/Kenya-EGS-Study-Final-

Report.pdf
Varlet-Gancher C, Bonhomme R, Sinoquet H (1993) Crop structure and light microclimate. Pp518

VSN International (2013) Genstat for Windows, 16th Edition. VSN International, Hemel Hempstead, UK. Web page: www.Gensat.co.uk

Wells R (1991) Soybean growth response to plant density: relationships among canopy photosynthesis, leaf area, and light interception. Crop Sci. 31:755-761.

Westgate ME (1999) Managing soybeans for photosynthetic efficiency. In: Kauffman H E (ed) World soybean research $\mathrm{VI}$ proceedings. World soybean research conference, Chicago, IL.

Whiting D (2011) Plant growth factors: light. CMG Garden notes. 142: 1-4. 